\title{
Letramentos sociais: abordagens críticas do letramento no desenvolvimento, na etnografia e na educação
}

\author{
Joelma dos Santos Barbosa Linhares Garcia ${ }^{1}$
}

\begin{abstract}
Resumo: O presente trabalho é uma resenha da obra de Street (2014) "Letramentos sociais: abordagens críticas do letramento no desenvolvimento, na etnografia e na educação", busca desenvolver abordagens alternativas que façam uma crítica às concepções de letramento como algo universal. Representa uma tendência que vem considerando o letramento e suas práticas associadas, numa perspectiva mais ampla, enfocando mais a natureza social da leitura e da escrita, bem como o seu caráter transcultural.
\end{abstract}

Palavras Chaves: Letramentos sociais. Etnografia. Leitura e escrita.

\section{Social literacies: critical literacy approaches in the development, ethnography and education}

\begin{abstract}
This paper is a review of the work of Street (2014) "Social Literacies: critical literacy approaches in the development, ethnography and education," seeks to develop alternative approaches to do a critique of literacy concepts as universal. It is a trend that has given literacy and its associated practices, in a broader perspective, focusing more on the social nature of reading and writing, as well as its cross-cultural character.
\end{abstract}

Key Words: Social Literacies. Ethnography. Reading and writing.

\section{Dados sobre a obra}

STREET, B.V. Letramentos sociais: abordagens críticas do letramento no desenvolvimento, na etnografia e na educação. Trad.: Marcos Bagno. São Paulo: Parábola Editorial, 2014. 240p.

Nesta obra, Street tenta caracterizar a natureza social do letramento, opondo-se a uma autonomia do processo de letramento, que é mais orientado para o desenvolvimento ou não de certas habilidades. Reconhece dessa forma, as diversas possibilidades de letramentos que são praticados em outros contextos mais sintonizados com outras realidades.

\footnotetext{
${ }^{1}$ Graduação em Ciências Econômicas pela Universidade Regional do Cariri; Graduação em Matemática pela Universidade Estadual do Ceará ; Graduação em Direito pela Faculdade de Filosofia, Ciências e Letras de Cajazeiras. Mestrado em Ciências da Educação Universidad Politécnica Y Artística Del Paraguay.
} 
Dessa forma, o autor sugere aos leitores que não aceitem a teoria de uma visão abrangente e etnocêntrica, que privilegia uma maneira particular de letramento, sabendo-se que são inúmeras as possibilidades de letramento. Street apresenta como proposta, um modelo de letramento, que leva em conta as práticas de leitura e escrita, inseridas não somente em significados culturais, mas em suas associações com a possibilidade de "poder" nas relações sociais implicadas.

\section{Análise do termo}

Com relação a terminologia adotada literacy, esta foi traduzida do inglês para a língua portuguesa como "letramento" ou "alfabetização". Tais terminologias, tem sido adotadas para relacionar diferentes campos da investigação científica, nas áreas de linguística, Educação, Antropologia, e outras, buscando definir uma espécie de uso social para a leitura e a escrita que estaria além da aquisição da linguagem propriamente dita. Dessa forma, o letramento, assim como a alfabetização, apesar de serem tomados algumas vezes como correlacionados e, talvez até complementares, na realidade referem-se a processos distintos (SOARES, 2004).

\section{Sobre o Letramento}

Dentre aqueles que têm trabalhado mais com as questões associadas ao letramento, o professor emérito da King's College London, Brian Vincent Street, tem se destacado através de suas muitas reflexões importantes, aqui postas (STREET, 2014).

Muitas pesquisas brasileiras na área da Linguagem, tem recorrido a trabalhos de Street, buscando práticas sociais de leitura e escrita, que sejam distintas daquelas práticas que parecem um processo óbvio de (de)codificação da língua. Este seria o caso, por exemplo, de Kleiman (1995). Este autor discute, com base em Street (1984), a relação entre assumir determinado modelo crítico em contrapartida às práticas letradas escolares, e a consequente possibilidade de sucesso (ou o fracasso) desses alunos, na construção de contextos mais transformadores da realidade, dos alunos letrados. 
A obra é uma abordagem crítica das características do letramento no desenvolvimento infantil. Trata de uma concepção de letramento universal. Esta parece uma perspectiva com tendência bem contemporânea, pois foca o letramento como uma prática social, enfatizando a natureza social da escrita e da leitura, valorizando uma perspectiva transcultural.

Street, quando enfatiza a natureza social do letramento, defende uma espécie de modelo ideológico, onde as práticas relativas ao letramentos são produtos de uma cultura, associadas as relações de poder (pág. 13). Esta perspectiva do autor se opõe a uma perspectiva mais centrada no sujeito, e nas suas capacidades individuais de manejar o texto escrito.

O autor refere um trabalho de campo realizado no Irã, nos anos 70, onde investigou o uso de significados contextuais no letramento. O que se observava como uma habilidade técnica, passa a ser concebido como uma prática ideológica, não neutra, embasada em relações de poder, que por sua vez são cheias de significados culturais específicos. Portanto, o autor reconhece existirem múltiplos letramentos que são praticados nos diversos contextos do cotidiano da vida real. O seu manuscrito parece adotar uma visão etnocêntrica, que privilegia o letramento de forma individualizada.

Street propõe ainda um modelo mais ideológico para o letramento, onde as práticas de escrita e de leitura estariam inseridas nos significados culturais e em posições ideológicas, base do letramento, segundo o autor.

Neste caso, o modelo mais autônomo tem propósitos políticos claros. O que implica numa divisão histórica entre os "povos lógicos" e os "povos pré-lógicos". Para isso, apresenta como evidências antropológicas, que existem pensamento científico e não-científico em quase todas as sociedades, bem como no imaginário de todos os indivíduos.

O discurso dos adeptos desse modelo mais autônomo de letramento, segundo Street (1984), é baseado na divisão entre letrados e não letrados. O que não envolve uma hierarquização entre as culturas. Neste caso, a suposta natureza técnica e/ou neutra do modelo autônomo de letramento, certamente absolveria seus adeptos. O que parece um equívoco.

Ainda com relação a concepção autônoma do letramento, a linguagem e suas funções seriam significativamente afetadas, no momento em que entra em cena a possibilidade da escrita, sobretudo das suas funções lógicas. A escrita seria um meio de habilitar seus usuários nas funções lógicas, o que não aconteceria necessariamente o mesmo, com relação a oralidade. 
O autor continua, orientando que, a falta do letramento, não necessariamente é uma barreira real para se conseguir um emprego, como podem sugerir algumas declarações públicas. Chega a citar Paulo Freire (1985), que sempre acreditou no potencial individual humanos, que mesmo não "letrados", seriam capazes de fazer uma "leitura" do mundo.

As teorias contemporâneas afirmam ser o letramento importante, mas que por si só, não é promotor de avanço cognitivo, de mobilidade social ou de progresso (pág.41).

O autor também se refere a um "letramento colonial", o processo de transferência de valores de uma cultura para outra e, denomina "letramento dominante" ao letramento onde um grupo dominante na sociedade é responsável por difundir o letramento e sua cultura, aos outros membros. Notório dizer que, esses valores da classe dominante, tendem a se inserir nessa atividade.

Street continua afirmando que, o modelo de letramento a ser adotado, precisa ser bem planejado e elaborado com vistas a uma certa complexidade que está implícita nas estruturas de poder, na cultura local e, nos significados do letramento para as pessoas que o recebem (p.53). O que é ensinado, requer uma discussão e uma análise, pois há muito espaço para reflexões e interpretações críticas.

$\mathrm{O}$ autor ainda enfatiza um processo ideológico enraizado no letramento, que propõe uma prática social, socialmente construída. Neste caso, a forma e o uso da leitura e da escrita estão atrelados a certas concepções do conhecimento, da identidade grupal e, dos modos de ser e estar nos contextos sociais. Portanto, os letramentos dos sujeitos estarão sempre dependentes desses contextos, e, das relações de poder predominantes.

A questão de partida que implicou na pesquisa foi: Existiriam múltiplos letramentos?, De que forma uma maneira particular passou a ser considerada como a forma mais correta de letramento? $\mathrm{O}$ autor afirma que o letramento, ocorreria também fora da escola e fora da pedagogia, Porém estaria implicado nessas instituições, de tal forma, que torna difícil o reconhecimento de sua presença em outras instituições sociais (pág.123).

Nesse sentido foi observado também algo sobre a linguagem do professor, bem como os seus textos, que tendem a posicionarem os sujeitos em suas carteiras e os localiza em um espaço social e autoritário. Street afirma que trata-se de uma questão a ser explorada. Sobre como e por que essa versão do letramento é construída, desse modo assimilada e internalizada nos diversos contextos, inclusive na própria escola (pág.140). 
Uma conclusão do autor é que a linguagem mascara e naturaliza muitas vezes, o papel ideológico do letramento. O letramento quando pedagogizado, torna-se um conceito definidor das ideias de identidade e valores sociais (pág.141).

Ele resume propondo que as pesquisas sobre letramento, não se concentrem apenas nas escolas isoladamente, mas envolvam as comunidades e as possibilidades de implicações de natureza ideológica, que estas tendem a eliciar.

Quanto mais o letramento se distanciar das práticas sociais de escrita e de leitura, mais estará sendo usado como significado das competências e/ou habilidades culturais.

Street afirma a importância dos professores neste processo, como planejadores, que precisam remeter a diferenças culturais, e a políticas específicas, a reflexão sobre a leitura e a escrita.

Remete ao método de Paulo Freire, quando comenta sobre as críticas suscitadas, em termos do perigo na formação das palavras, sem que haja um domínio dos hábitos de leitura por parte dos aprendizes (BARTON e HAMILTON, 1998).

Refere-se ainda a Rogers (1983, p.34), quando afirma que o letramento sozinho não é capaz de empoderar. As elites detêm o poder, e isso não é por conta do letramento, embora usem o letramento para sustentar o próprio poder.

\section{Conclusão}

O autor informa principalmente, que é preciso nos concentrar, como educadores, em alguns pontos chave (p.211): a) Como é possível ajudar os participantes no processo de letramento, de maneira a facilitar aos mesmos um letramento contextualizado e apropriado a sua realidade? b) Como engajar o letramento individual, de maneira que este possa se construir mais sintonizado com a realidade familiar, maturacional e cultural da criança.

\section{Referências}


STREET, B.V. Letramentos sociais: abordagens críticas do letramento no desenvolvimento, na etnografia e na educação. Trad.: Marcos Bagno. São Paulo: Parábola Editorial, 2014. $240 \mathrm{p}$.

Rogers, C. Um jeito de ser. São Paulo: E.P.U, 1983;

BARTON, D.; HAMILTON, M. Local literacies: reading and writing in one community. London: Routledge, 1998.

FREIRE, P. A importância do ato de ler. São Paulo: Cortez/Autores Associados, 1985.

KLEIMAN, A. Modelos de letramento e as práticas de alfabetização na escola. In: KLEIMAN, A.(Org.).Os significados do letramento: uma nova perspectiva sobre a prática social da escrita. Campinas: Mercado de Letras, 1995. p. 15-64.

SOARES, M. Letramento e alfabetização: as muitas facetas. Revista Brasileira de Educação, Rio de Janeiro, n.25, Abr, 2004

\section{Como citar este artigo (Formato ABNT):}

GARCIA, J.S.B.L. Letramentos sociais: Abordagens Críticas do Letramento no Desenvolvimento, Etnografia e Na Educação. Id on Line Revista Multidisciplinar e de Psicologia, Julho de 2016, vol.10, n.30, Supl 2. p. 245 a 250. ISSN 1981-1179.

Recebido: 05/05/2016

Aceito: 17/05/2016 